At Turots: Jurnal Pendidikan Islam
Vol. 2, No. 2, Desember 2020, pp. 180-187
Print ISSN : 2656-7555 || Online ISSN : 2747-089X
http://journal.stitmadani.ac.id/index.php/JPI/index

\title{
Metode pendidikan agama Islam dalam al-Qur'an
}

\author{
Sugeng Priyanto a,1, ${ }^{*}$, Darwin Hamisi a,2, Evi Octaviana ${ }^{b, 3}$ \\ *a Sekolah Tinggi Ilmu Tarbiyah Madani Yogyakarta, Indonesia; \\ b STAINU Temanggung, Indonesia. \\ ${ }^{1}$ priasugengjogja@gmail.com; ${ }^{2}$ darwinhamisjg@gmail.com; ${ }^{3}$ evi.okta0001@gmail.com \\ *Correspondent Author
}

\section{KATAKUNCI}

Metode

Pendidikan Agama Islam

Ayat al Qur'an

KEYWORDS

Methods

Islamic religion education Qur'an verses
ABSTRAK

Penelitian ini menjelaskan tentang metode pendidikan agama Islam yang terdapat dalam al-Qur'an serta termasuk ke dalam jenis penelitian studi pustaka atau literer. Ada delapan metode pendidikan agama Islam yang terdapat dalam al-Qur'an, meskipun sebenarnya masih banyak metode pendidikan agama Islam lain yang belum bisa tersajikan karena keterbatasan penelitian ini. Delapan metode tersebut adalah metode Kisah, Amtsal, Ibrah-Mau'idzoh, Targhib dan Tarhib, Ceramah, Keteladanan, dan Diskusi. Dalam implementasinya, kedelapan metode tersebut diterapkan secara variatif sehingga mampu mengakomodir gaya belajar peserta didik. Ayat yang mengandung tentang metode pendidikan agama Islam antara lain di dalam alQur'an kata diskusi sama dengan al-mujadallah itu diulang sebanyak 29 kali, salah satunya terdapat pada surat al-Nahl ayat 125. Metode keteladanan tersirat dalam al Quran yaitu Q.S An Nisa ayat 48. Contoh penerapan metode Tanya jawab yang paling jelas terdapat didalam surat Ar-Rahman ayat 13. Ceramah adalah metode yang cara penyampaiannya melalui penuturan secara lisan oleh pendidik kepada seorang peserta didik. Prinsip dasar metode ini terdapat di dalam Q.S Yunus ayat 23.

\section{Methods of Islamic religious education in the Qur'an}

This study describes the method of Islamic religious education contained in the Qur'an and is included in the type of literature or literary research. There are eight methods of Islamic religious education contained in the Qur'an, although in fact there are still many other methods of Islamic religious education that cannot be presented due to the limitations of this study. The eight methods are the Story method, Proverbs, Ibrah-Mau'idzoh, Targhib and Tarhib, Lectures, Exemplary, and Discussion methods. In its implementation, the eight methods are applied in various ways so that they are able to accommodate the learning styles of students. The verse that contains the method of Islamic religious education, among others, in the Qur'an, the word discussion is the same as al-mujadallah, is repeated 29 times, one of which is in Surah al-Nahl verse 125. The exemplary method is implied in the Qur'an, namely QS An Nisa verse 48. The clearest example of the application of the question and answer method is contained in the letter Ar-Rahman verse 13. Lecture is a method in which the method of delivery is through oral narrative by an educator to a student. The basic principle of this method is contained in Q.S Yunus verse 23.

This is an open-access article under the CC-BY-SA license. 


\section{Pendahuluan}

Dalam pendidikan yang Islami, perlu dipergunakan metode pendidikan yang dapat melakukan pendekatan menyeluruh terhadap manusia, meliputi dimensi jasmani dan rohani (lahiriah dan batiniah)(Masykur, 2020), walaupun tidak ada satu jenis metode pendidikan yang paling sesuai mencapai tujuan dengan semua keadaan. Metode pendidikan memiliki peran yang strategis dalam mencapai tujuan pendidikan. Tanpa adanya metode, maka proses pencapaian tujuan pendidikan akan terhambat bahkan tidak berhasil sama sekali. Oleh karena itu penting bagi pendidik atau guru untuk menguasai banyak metode dalam melaksanakan kegiatan mendidik. Sebenarnya banyak literatur-literatur yang membahas tentang metode pendidikan yang dapat digunakan sebagai rujukan dalam melaksanakan tugas mendidik. Namun sebagai pendidik, menjadi penting juga untuk mengkaji, menemukan, dan menggunakan metode-metode yang bersumber dari ajaran agama yakni al-Qur'an.

Metode berasal dari dua kata yaitu "Meta" yang artinya melalui, dan "Hodos" yang artinya jalan atau cara.(Zamzam, 2017) Dalam Kamus Besar Bahasa Indonesia dijelaskan bahwa metode adalah cara yang teratur digunakan untuk melaksanakan suatu pekerjaan agar tercapai sesuai dengan apa yang dikehendaki.(Bahasa, 2020) Menurut Abuddin Nata,(Poloso, 2018) metode dapat diartikan sebagai cara atau jalan yang harus dilalui untuk mencapai tujuan. Selain itu ada juga yang mengatakan bahwa metode adalah suatu saran untuk menemukan, menguji, dan menyusun data yang diperlukan bagi pengembangan disiplin ilmu.

Sedangkan pendidikan menurut Abdurrahman Annahlawi (Nurjannah, 2015)pendidikan dalam konteks islam juga memiliki beberapa pengertian diantaranya at- tarbiyah, at-ta'lim, dan at-ta'dib. Menurut Ahmad Tafsir, yang dimaksud dengan metode pendidikan islam(WARDI, 2017) adalah semua cara yang digunakan dalam upaya mendidik.

Tidaklah berlebihan jika ada sebuah ungkapan "aththariqah ahammu minal maddah", bahwa metode jauh lebih penting dibanding materi, karena sebaik apapun tujuan pendidikan, jika tidak didukung oleh metode yang tepat, tujuan tersebut sangat sulit untuk dapat tercapai dengan baik. Sebuah metode akan mempengaruhi sampai tidaknya suatu informasi secara lengkap atau tidak.. Oleh sebab itu pemilihan metode pendidikan harus dilakukan secara cermat, disesuaikan dengan berbagai faktor terkait, sehingga hasil pendidikan dapat memuaskan. Apa yang dilakukan Rasulullah SAW saat menyampaikan wahyu Allah kepada para sahabatnya bisa kita teladani, karena Rasul saw. sejak awal sudah mengimplementasikan metode pendidikan yang tepat terhadap para sahabatnya. Strategi pembelajaran yang beliau lakukan sangat akurat dalam menyampaikan ajaran Islam. Rasul saw. sangat memperhatikan situasi, kondisi dan karakter seseorang, sehingga nilai-nilai Islami dapat ditransfer dengan baik. Rasulullah saw. juga sangat memahami naluri dan kondisi setiap orang, sehingga beliau mampu menjadikan mereka suka cita, baik meterial maupun spiritual, beliau senantiasa mengajak orang untuk mendekati Allah swt. dan syari'atNya.

\section{Metode}

Penelitian ini digolongkan ke dalam jenis penelitian studi pustaka atau literer,(Moto, 2019) yaitu dalam proses perolehan data sesuai dengan sasaran atau masalah penelitian yang diperlukan sebuah informasi yang selengkap- lengkapnya atau sedalamdalamnya mengenai gejala-gejala yang ada dalam lingkup obyek penelitian. Dari gejala-gejala penelitian yang ada dalam penelitian ini bukanlah satu-satunya yang berdiri, melainkan saling berkaitan antara satu sama lain dalam kesatuan yang menyeluruh yang biasanya dikenal dengan pendekatan . Dalam penelitian ini, pengumpulan data menggunakan tiga metode utama yaitu : wawancara, observasi dan dokumentasi. 


\section{Hasil dan Pembahasan}

Al Qur'an merupakan sember utama ajaran islam yang wajib dipahami oleh setiap muslim, menampilkan metode dan cara yang menarik, sehingga mudah dipahami atau dipelajari. Adapun metode - metode yang ada dalam Al Qur'an(Pito, 2019) yaitu:

\section{Metode Kisah (Cerita)}

Di dalam Al Qur'an mengandung banyak kisah - kisah tentang orang - orang terdahulu. Rosulullah SAW dapat mengetahui kisah -kisah nabi dan umat sebelumnya melalui cerita yang ada di dalam Al Qur'an, yaitu Q.S Thahaa ayat 99 yang artinya "Demikianlah kami kisahkan kepadamu (Muhammad) sebagian kisah umat yang telah lalu, dan sesungguhnya telah kami berikan kepadamu dari sisi kami suatu peringatan (Al Qur'an)."

Contoh kisah yang ada dalam Al Qur'an yaitu: Kisah Nabi Yusuf, terdapat dalam Q.S Yusuf ayat, Kisah Nabi Musa, dan Kisah Ashabul Kahfi.

Metode bercerita juga terdapat dalam QS. Huud ayat 120 Yang artinya "Dan semua kisah dari rasul-rasul kami ceritakan kepadamu, ialah kisah-kisah yang dengannya kami teguhkan hatimu; dan dalam surat Ini telah datang kepadamu kebenaran serta pengajaran dan peringatan bagi orang-orang yang beriman."

Ayat ini menerangkan bahwa Allah swt. telah menceritakan kisah rasul-rasul terdahulu bersama umatnya, seperti peristiwa perbantahan dan permusuhan di antara mereka, diselamatkannya umat yang beriman dan diazabnya kaum yang tidak beriman, keluhan para Nabi karena kaumnya mendustakan dan menyakitinya dan sebagainya, semuanya itu berguna untuk meneguhkan hati Rasulullah SAW, laksana gunung yang tak tergoyahkan oleh apa pun untuk mengemban tugas kerasulan dan menyiarkan dakwahnya karena telah mencontoh kepada rasul-rasul sebelumnya yang telah mendapat tantangan hebat sekali dari kaumnya. Selain dari itu, kisah-kisah tersebut juga menanamkan kebenaran yang mantap, keyakinan yang mendalam tentang apa yang diserukan para Rasul, seperti akidah bahwa Allah azza wajalla. adalah Esa, bertobat dan beribadah kepada-Nya dengan ikhlas, meninggalkan kejahatan baik yang nyata maupun yang tidak nyata. Kesemuanya itu merupakan pengajaran dan peringatan yang bermanfaat bagi orang-orang yang percaya bahwa umat terdahulu itu ditimpakan azab kepadanya adalah karena mereka telah berbuat aniaya dan kerusakan di muka bumi. Imam at-Thabari juga memberI penjelasan tentang ayat ini bahwa Allah swt berfirman : segala yang Kami ceritakan kepada kamu (Muhammad) tentang cerita para Rasul (orang-orang sebelum kamu), yaitu cerita yang dapat memantapkan hati kamu, maka janganlah susah dengan kedustaan kaummu, dan menolak apa yang telah kamu sampaikan kepada mereka, dan janganlah berkecil hati sehingga kamu meninggalkan sebagian yang telah Kami turunkan kepadamu, sekiranya mereka berkata : tidakkah diturunkan kepadanya rahasia langit atau malaikat datang bersamanya? ketika kamu telah mengetahui apa yang telah dihadapi oleh para Rasul sebelum kamu dan umat mereka.

Begitu juga terdapat hadits Nabi yang senada dengan metode cerita tersebut, seperti hadits Abu Hurairah ra, yang artinya : Artinya: "Dari Abu Hurairah ra, sesungguhnya rasulullah SAW bersabda: Ketika seorang laki-laki sedang berjalanjalan tiba-tiba ia merasa sangat haus sekali kemudian ia menemukan sumur lalu ia masuk kedalamnya dan minum, kemudian ia keluar (dari sumur). Tiba-tiba datang seekor anjing menjulur-julurkan lidahnya ia menjilati tanah karena sangat haus, lelaki itu berkata: anjing itu sangat haus sebagaimana aku, kemudian masuk ke sumur lagi dan ia penuhi sepatunya (dengan air), kemudian ia sambil menggigit sepatunya dan ia beri minum anjing itu kemudian Allah bersyukur kepadanya dan mengampuninya, sahabat bertanya, wahai Rasulullah: adakah kita mendapat pahala karena kita menolong hewan? Nabi SAW menjawab: disetiap yang mempunyai limpa hidup ada pahalanya. (HR. Bukhori). 
Dalam metode bercerita jika di terapkan pada masa sekarang tentunya baik karna dalam metode ini tingal hanya mendegarkan namun dalam metode ini tentunya sebagai pembicara harus lebih meguasai materi yang akan di sampaikan dan dan kreatif dalam penyampaiannya

\section{Metode Amtsal (Perumpamaan)}

Amtsal adalah bentuk jamak dari kata matsal dan mitsil. "matsal" mengandung arti cerita - cerita perumpamaan.(Makrifah, 2020) Sedangkan menurut istilah penyerupaan suatu keadaan dengan keadaan yang lain, demi mencapai tujuan yang sama., yaitu pengisah menyerupakan sesuatu dengan aslinya. Dalam kamus bahasa Indonesia amsal adalah umpama atau perumpamaan. Contoh - contoh perumpamaan dalam al Qur'an surat al Baqarah ayat 17 yang artinya "Perumpamaan mereka adalah seperti orang yang menyalakan api, maka setelah api itu menerangi sekelilingnya Allah hilangkan cahaya yang menyinari mereka, dan membiarkan mereka dalam kegelapan, tidak dapat melihat."

Metode ini relevan jika digunakan dalam pembelajaran saat ini. Karena metode amtsal ini merupakan cara mengajar dimana guru menyampaikan materi pembelajaran melalui contoh atau perumpamaan.

\section{Metode Ibrah - Mauidzhah ( Nasihat )}

Ibrah adalah mengambil contoh dan pelajaran dari pengalaman yang telah lalu. Sedangkan mauizhah yaitu nasehat atau pelajaran. (Aziz et al., 2020) Contoh nasehat dalam Al Qur'an surat an Nuur ayat 44 yang artinya "Allah mempergantikan malam dan siang. Sesungguhnya pada yang demikian itu terdapat pelajaran yang besar bagi orang -orang yang mempunyai penglihatan".

Sebuah nasehat dapat dijadikan salah satu metode dalam pendidikan dengan alasan mengandung pelajaran yang penting dalam pendidikan dan nasehat dilakukan berulang ulang, agar nasehat itu meninggalkan kesan sehinggaorang yang dinasehati tergerak untuk mengikuti nasehat itu.

\section{Metode Targhib dan Tarhib (Penghargaan dan Hukuman)}

Targhib adalah janji yang disertai dengan bujukan, bujukan yang dimaksud adalah kesenangan duniawi dan ukhrawiakibat melakukan suatu perintah dan larangan allah. Sedangkan tarhib adalah ancaman dengan siksaan sebagai akibat melakukan dosa dan kesalahan yang dilarang oleh Allah, atau tidak melaksanakan perintahnya.(Nur \& Hasnawati, 2020) Contoh Targhib dalam Al Qur'an yaitu surat Ar Ra'd ayat 35 yang artinya "Perumpamaan surga yang dijanjikan kepada orang - orang yang takwa adalah (seperti taman) mengalir sungai -sungai di dalamnya, buahnya tak henti - henti sedang naunganya (demikian pula). Itulah tempat kesudahan bagi orang - orang uang bertakwa, sedangkan tempat terakhir bagi orang - orang kafir adalah neraka". Contoh Tarhib dalam Al Qur'an surat Al Isra' ayat 32 yang artinya "Dan janganlah kamu mendekati zina, sesungguhnya zina itu adalah suatu perbuatan yang keji dan suatu jalan yang buruk".

Metode ini juga relevan jika digunakan pembelajaran pada saat ini, karena merupakan cara mengajar dimana guru memberikan materi pembelajaran dengan menggunakan ganjaran terhadap kebaikan dan hukuman terhadap keburukan agar peserta didik melakukan kebaikan dan menjauhi keburukan.

\section{Metode Ceramah}

Ceramah adalah metode yang cara penyampaiannya melalui penuturan secara lisan oleh pendidik kepada seorang pendidik.(Maurin \& Muhamadi, 2018) Prinsip dasar metode ini terdapat di dalam Q.S Yunus ayat 23 yang Artinya "Maka tatkala Allah menyelamatkan mereka, tiba - tiba mereka berbuat kedzhaliman di muka bumi tanpa alasan yang benar. Hai manusia, sesungguhnya bencana kezhalimanmu akan menimpa dirimu sendiri, hasil kedzhalimanmu itu hanyalah kenikmatan duniawi, kemudian kepada kamilah kembalimu, 
lalu kami kabarkan kepadamu apa yang telah kami kerjakan".

\section{Metode Tanya Jawab}

Tanya jawab merupakan salah satu metode yang menggunakan basis anak didik menjadi pusat pembelajaran.(Sitohang, 2017) Metode ini bisa dimodif sesuai dengan pelajaran yang akan disampaikan. Bisa anak didik yang bertanya dan guru yang menjawab atau bisa anak didik yang menjawab pertanyaan dari gurunya. Di dalam al-Qur'an hal ini juga digunakan oleh Allah agar manusia berfikir. Adapun contoh yang paling jelas dari metode pendidikan Qur'an terdapat didalam surat Ar-Rahman. Disini Allah SWT mengingatkan kepada kita akan nikmat dan bukti kekuasaan-Nya, dimulai dari manusia dan kemampuannya dalam mendidik, hingga sampai kepada matahari, bulan, bintang, pepohonan, buah-buahan, langit dan bumi. Pada setiap ayat atau beberapa ayat dengan kalimat bertanya itu, manusia berhadapan dengan indera, naluri, suara hati dan perasaan. Ayat itu adalah Ar-Rahman ayat 13 : Artinya : Maka nikmat rabb kalian yang manakah yang kalian dustakan?”( Qs. Ar Rahman : 13 ). Pertanyaan itu diulang sebanyak 31 kali didalam surat ini. Setiap diulang, pertanyaan itu merangsang kesan yang berlainan sesuai dengan konteksnya dengan ayat sebelumnya.

Metode tanya jawab terdapat pada QS. al-Baqarah ayat 189. Yang artinya : Mereka bertanya kepadamu tentang bulan sabit. Katakanlah: "Bulan sabit itu adalah tanda-tanda waktu bagi manusia dan (bagi ibadat) haji; dan bukanlah kebajikan memasuki rumah-rumah dari belakangnya, akan tetapi kebajikan itu ialah kebajikan orang yang bertakwa. dan masuklah ke rumah-rumah itu dari pintu-pintunya; dan bertakwalah kepada Allah agar kamu beruntung.

Pada ayat tersebut terdapat tiga keterangan, yaitu tentang pertanyaan sahabat tentang hilal beserta jawabannya, keterangan tentang memasuki rumah melalui pintunya, dan perintah bertakwa kepada Allah. Dari hal ini kita mengetahui terjadi tanya jawab antara sahabat dengan Nabi Muhammad saw. Mengenai sebab turunya ayat ini Muhamad al-Alusy Abu Fadl menerangkan dalam kitabnya bahwa Ibnu Asakir menceritakan dengan sanad dhoif bahwa Mu'ad bin Jabbal dan Tsa'labah bin Ghanam bertanya kepada Rasul : Ya Rasulallah Bagaimana keadaan hilal yang nampak dan muncul kecil seperti benang, kemudian bertambah besar, rata dan bulat, kemudian terus menerus berkurang dan mengecil sehingga kembali seperti semula, bulan itu tidak menetapi pada bentuk yang tetap (satu bentuk)? Kemudian turunlah ayat tersebut.

Tentang metode tersebut juga senada dengan sebuah hadits Nabi Muhammad saw yang diriwayatkan oleh Imam Muslim yang artinya : Artinya: "Hadis Qutaibah ibn Sa'id, hadis Lâis kata Qutaibah hadis Bakr yaitu ibn Mudhar dari ibn Hâd dari Muhammad ibn Ibrahim dari Abi Salmah ibn Abdurrahmân dari Abu Hurairah r.a. Rasulullah saw. bersabda; Bagaimana pendapat kalian seandainya ada sungai di depan pintu salah seorang di antara kalian. Ia mandi di sana lima kali sehari. Bagaimana pendapat kalian? Apakah masih akan tersisa kotorannya? Mereka menjawab, tidak akan tersisa kotorannya sedikitpun. Beliau bersabda; Begitulah perumpamaan salat lima waktu, dengannya Allah menghapus dosa-dosa". (Muslim, I: 462-463)

Metode tanya jawab merupakan metode yang sangat baik karna dalam metode ini guru harusmenjawab pertanyaan pertanyaan yang di sampaikan dan guru juga bisa menilaidengan mudah ketika ada murid yang aktif bertanya berarti murid itu memperhtikan begitu pula murid akan lebih berani dalam mengutarakan pendapatnya

\section{Metode Keteladanan}

Keteladanan dalam arti bahasa adalah hal yang dapat ditiru atau dicontoh.(Sitompul, 2018) Peneladanan ada dua macam yaitu sengaja dan tidak sengaja. Keteladanan sengaja ialah keteladanan yang disertai penjelasan, seperti memberikan contoh membaca yang baik, mengajarkan sholat yang benar dan sebagainya. Keteladanan tidak sengaja ialah keteladanan 
yang tidak disertai penjelasan, seperti keteladanan dalam keilmuaan, kepemimpinan, sifat keikhlasan dan lain-lain. Contoh keteladan terdapat di dalam Al Quran surat An Nisa ayat 48 yang artinya "Nabi Ibrahim pernah memintakan ampunan bagi bapaknya yang musyrik kepada Allah : Ini tidak boleh ditiru, Karena Allah tidak membenarkan orang mukmin memintakan ampunan untuk orang-orang kafir."

\section{Metode Diskusi}

Metode diskusi (Kelirik, 2019)diperhatikan dalam al-Qur'an dalam mendidik dan mengajar manusia dengan tujuan lebih memantapkan pengertian dan sikap pengetahuan mereka terhadap sesuatu masalah. Sama dengan metode diatas metode diskusi merupakan salah satu metode yang secara tersirat ada dalam al-Qur'an. Di dalam al Qur'an kata diskusi sama dengan al-mujadallah itu diulang sebanyak 29 kali. Diantaranya adalah pada surat alNahl ayat 125 yang artinya "Dan bantahlah dengan cara yang baik."

Dari ayat diatas Allah telah memberikan pengajaran bagi umat Islam agar membantah atau berargument dengan cara yang baik. Dan tidak lain itu bisa kita temui dalam rangkaian acara yang biasa disebut diskusi. Diskusi juga merupakan metode yang langsung melibatkan anak didik untuk aktif dan kreatif dalam pembelajaran. Diskusi bisa berjalan dengan baik jika anak didik yang menduskisikan suatu materi itu benar-benar telah menguasai sebagian dari inti materi tersebut. Akan tetapi jika peserta diskusi yakni anak didik tidak paham akan hal tersebut maka bisa dipastikan diskusi tersebut tidak sesuai yang diharapkan dalam pembelajaran.

Metode ini terdapat dalam QS. Nahl ayat 125, yang artinya : Serulah (manusia) kepada jalan Tuhan-mu dengan hikmah dan pelajaran yang baik dan bantahlah mereka dengan cara yang baik. Sesungguhnya Tuhanmu dialah yang lebih mengetahui tentang siapa yang tersesat dari jalan-Nya dan dialah yang lebih mengetahui orang-orang yang mendapat petunjuk. Hal ini diketahui dari kata bantahlah mereka dengan bantahan yang paling baik atau dengan kata lain berdiskusilah dengan mereka melalui cara yang terbaik. Hal ini dapat menjadi inspirasi untuk melalukan pendidikan melalui metode diskusi. Menurut Quraish Shihab, kata jâdilhum terambil dari kata jidâl yang bermakna diskusi atau buktibukti yang mematahkan alasan atau dalih mitra diskusi dan menjadikannya tidak dapat bertahan, baik yang dipaparkan itu diterima oleh semua orang maupun hanya mitra bicara. Selanjutnya, jadil juga adalah perdebatan dengan cara yang terbaik yaitu dengan logika dan retorika yang halus, lepas dari kekerasan dan umpatan.

Dalam tafsirnya, Jalaluddin Abdurrahman bin Abi Bakar as-Suyuti menjelaskan kalimat tersebut maksudnya : "debatlah mereka dengan debat (yang terbaik) seperti menyeru manusia kepada Allah dengan ayat-ayat-Nya dan menyeru manusia kepada hujah Jadi dalam ayat tersebut dapat dipahami bahwa metode mujadalah atau diskusi dapat menjadi sebuah metode pendidikan yang tepat untuk mendapatkan kebenaran melalui hujjah-hujjah atau argument-argument yang disampaikan dengan etika yang baik tidak merasa paling benar atau arogan, guru lebih mudah untuk mengarahkan peerta didik, begitu pula peserta didik dapat lebih active dalam kegiatan belajar mengajar

Mengenai motede diskusi ini terdapat sebuah hadits riwayat Imam Bukhari yang relevan, yang artinya : "telah menceritakan kepadaku Muhammad bin Abdu ar Rahim dari sa'id bin Sulaiman dari hasyim dari Abdullah bin Abi Bakr bin Anas dari Annas ra, berkata: Rasulullah SAW, bersabda: "tolonglah saudaramu yang dzalim dan yang didzalimi, kemudian seorang laki-laki bertanya: Ya Rasulallah aku menolongnya ketika terdzalimi, bagaimana jika menolong orang yang dzalim? Rasulullah menjawab: tahanlah (hentikanlah) dia dari kedzalimannya, karena sesungguhnya itu merupakan pertolongan padanya". (HR. Bukhari). 


\section{Simpulan}

Berdasarkan hasil Penelitian ini, menunjukkan bahwa ada delapan metode pendidikan agama Islam yang terdapat dalam al-Qur'an, meskipun sebenarnya juga masih banyak metode pendidikan agama Islam lain yang belum mampu tersajikan karena keterbatasan penelitian ini. Delapan metode tersebut antara lain metode Kisah, Amtsal, Ibrah-Mau'idzoh, Targhib dan Tarhib, Ceramah, Keteladanan, dan Diskusi. Dalam implementasinya, kedelapan metode tersebut diterapkan secara variatif sehingga mampu mengakomodir gaya belajar peserta didik.

Ayat yang mengandung tentang metode pendidikan agama Islam antara lain di dalam alQur'an kata diskusi sama dengan al-mujadallah itu diulang sebanyak 29 kali, salah satunya terdapat pada surat al-Nahl ayat 125. Metode keteladanan tersirat dalam al Quran yaitu Q.S An Nisa ayat 48. Contoh penerapan metode Tanya jawab yang paling jelas terdapat didalam surat Ar-Rahman ayat 13. Ceramah adalah metode yang cara penyampaiannya melalui penuturan secara lisan oleh pendidik kepada seorang peserta didik. Prinsip dasar metode ini terdapat di dalam Q.S Yunus ayat 23.

Contoh Targhib dalam Al Qur'an yaitu terdapat dalam Q.S Ar Ra'd : 35, adapun contoh Tarhib dalam Al Qur'an yaitu terdapat dalam Q.S Al Isra' : 32. Selanjutnya, Ibrah adalah mengambil contoh dan pelajaran dari pengalaman yang telah lalu. Sedangkan mauizhah yaitu nasehat atau pelajaran. Contoh - contoh nasehat dalam al Qur'an ayat 44. Contoh perumpamaan dalam Q.S Al Baqarah ayat 17. Di dalam Al Qur'an mengandung banyak kisah kisah tentang orang - orang terdahulu. Rasulullah Sholallahu 'Alaihi wa Salam dapat mengetahui kisah -kisah nabi dan umat sebelumnya melalui cerita yang ada di dalam Al Qur'an, yaitu Q.S Thahaa ayat 99.

\section{Daftar Pustaka}

Aziz, A. A., Budiyanti, N., \& Hasanah, A. (2020). PENGEMBANGAN MODEL IBRAH MAUIDZAH DALAM PEMBELAJARAN PAI UNTUK MENINGKATKAN KARAKTER SISWA. At-Tajdid : Jurnal Pendidikan Dan Pemikiran Islam, 4(01), 46. https://doi.org/10.24127/att.v4i01.1218

Bahasa, B. P. dan P. (2020). KBBI Daring. Kementerian Pendidikan, Kebudayaan, Riset, Dan Teknologi Republik Indonesia. https://kbbi.kemdikbud.go.id/entri/metode

Kelirik, N. (2019). Penerapan Metode Diskusi Kelompok Untuk Meningkatkan Hasil Belajar Ipa Di Sekolah Dasar Negeri 1 Sukadana. Jurnal IKA, 16(1), 1. https://doi.org/10.23887/ika.v16i1.19821

Makrifah, N. (2020). Macam Urgensi Amtsal Dalam Al-Quran. At-Turost : Journal of Islamic Studies, 7(2), 216-232. https://doi.org/10.52491/at.v7i2.21

Masykur, F. (2020). Dimensi-dimensi Pendidikan dalam Islam. Tarbawi, 3, 19.

Maurin, H., \& Muhamadi, S. I. (2018). Metode Ceramah Plus Diskusi dan Tugas Untuk Meningkatkan Aktivitas Belajar Siswa. Al-Aulad: Journal of Islamic Primary Education, 1(2), 65-76. https://doi.org/10.15575/al-aulad.v1i2.3526

Moto, M. M. (2019). Pengaruh Penggunaan Media Pembelajaran dalam Dunia Pendidikan. Indonesian Journal of Primary Education, 3(1), 20. https://doi.org/10.17509/ijpe.v3i1.16060

Nur, S., \& Hasnawati, H. (2020). Metode Targhib dan Tarhib dalam Pendidikan Islam. AL-LIQO: Jurnal Pendidikan Islam, 5(01), 64-77. https://doi.org/10.46963/alliqo.v5i01.145

Nurjannah, R. (2015). Pendekatan dan Metode Pendidikan Islam (Sebuah Perbandingan dalam Konsep Teori Pendidikan Islam dan Barat). Jurnal: Management of Education, 1(2), 105-117. 
Pito, A. H. (2019). Metode Pendidikan dalam Al-Qur'an. Andragogi: Jurnal Diklat Teknis Pendidikan Dan Keagamaan, 7(1), 113-129. https://doi.org/10.36052/andragogi.v7i1.74

Poloso, R. (2018). Epistemologi Pendidikan Islam Perspektif Abuddin Nata. Farabi, 15(2), 82-102. https://doi.org/10.30603/jf.v15i2.645

Sitohang, J. (2017). Penerapan Metode Tanya Jawab untuk Meningkatkan Hasil Belajar IPA Pada Siswa Sekolah Dasar. Suara Guru : Jurnal Ilmu Pendidikan Sosial, Sains, Dan Humaniora, 3(4), 681-688.

Sitompul, H. (2018). Metode Keteladanan Dan Pembiasaan Dalam Penanaman Nilai-Nilai Dan Pembentukan Sikap Pada Anak. Pembentukan Anak Usia Dini : Keluarga, Sekolah, Dan Komunitas, 2(01), 15.

WARDI, M. (2017). Metode Pendidikan Islam Menurut Ahmad Tafsir. FIKROTUNA, 3(1). https://doi.org/10.32806/jf.v3i1.89

Zamzam, F. (2017). Metode Pendidikan Islam Perspektif Hadis Rasulallah saw. Jurnal Sabilarrasyad, $11(2), 72$. 